\title{
Protective Effect of the Nuclear Factor Kappa B Inhibitor Pyrrolidine Dithiocarbamate in Lung Injury in Rats with Streptozotocin-Induced Diabetes
}

\author{
Gulay Eren $^{\mathrm{a}}$ Zafer Cukurova $^{\mathrm{a}}$ Oya Hergunsel ${ }^{\mathrm{a}}$ Guray Demir ${ }^{\mathrm{a}}$ Mine Kucur $^{\mathrm{d}}$ \\ Ezel Uslu ${ }^{d}$ Enis Dalo ${ }^{d}$ Mehmet Uhrib Volkan Tugcu ${ }^{c}$

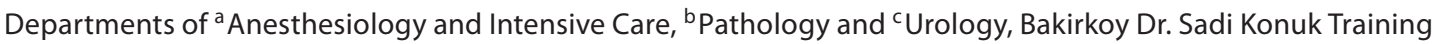 \\ and Research Hospital, and d Department of Biochemistry, Istanbul University, Cerrahpasa Medical Faculty, \\ Istanbul, Turkey
}

\section{Key Words}

Diabetic complications - Lung injury • Oxidative stress •

Nitric oxide synthase, endothelial • Nuclear factor kappa B

\begin{abstract}
Background: Diabetes mellitus (DM) causes debilitating complications and, as a result, diabetics frequently require intensive care. Although lungs are not thought to be affected primarily by DM, an increasing number of studies indicate physiological and structural abnormalities in diabetic lungs. Objectives: Pyrrolidine dithiocarbamate (PDTC) is a metal chelator and a potent inhibitor of NF- $\mathrm{B}$. Keeping in mind that NF- $\kappa$ B activation may be crucial in end-organ injury due to $D M$, we studied the role of PDTC on the inhibition of NF- $\kappa B$ activation and its effects on possible lung injury in rats with streptozotocin-induced DM. Methods: 36 Sprague-Dawley rats were allocated into 4 groups: diabetes, diabetes + PDTC, control and control + PDTC. At the end of 10 weeks, rats were sacrificed and their lungs were taken for histopathological and immunohistochemical evaluation [for NF- $\mathrm{KB}$ (p65) and endothelial nitric oxide (eNOS) immunoreactivities]. Protein carbonyl content (PCC), superoxide dismutase (SOD) and reduced glutathione (GSH) activities were
\end{abstract}

measured. Results: Histopathologically, basal membranes were thickened and there was intense inflammatory reaction in diabetic lungs. However, the PDTC group, in which there were poor positive expressions of eNOS and p65 activity compared to diabetes group, revealed fewer inflammatory changes. PCC levels in diabetic lungs were higher, but SOD and GSH activities were lower. However, measurements of these parameters in the PDTC group and controls gave similar results. Conclusion: Lungs are exposed to changes induced by oxidative stress in diabetes through NF- $\mathrm{KB}$ activation and PDTC seems to be useful to prevent diabetic lung injury.

Copyright $\odot 2009$ S. Karger AG, Basel

\section{Introduction}

Diabetes mellitus (DM) affects approximately 6\% of the world's population and this is set to rise to 300 million sufferers by 2025. Most hospitalizations are triggered by infection (29\%) or non-compliance with medication (17\%) in previously diagnosed diabetics [1]. The range of severity of presentation is very wide and diabetics often require intensive care admission because of its debilitat-

\section{KARGER}

Fax +41613061234 E-Mail karger@karger.ch www.karger.com
(C) 2009 S. Karger AG, Basel

0025-7931/10/0795-0402\$26.00/0

Accessible online at:

www.karger.com/res
Volkan Tugcu, MD

Department of Urology, Bakirkoy Dr. Sadi Konuk Training and Research Hospital

Zuhuratbaba, Bakirkoy

TR-34147 Istanbul (Turkey)

Tel.+90 212414 7248,Fax +90 212542 4491, E-Mail volkantugcu@yahoo.com 
ing complications. Intensive care unit admission may be indicated in end-organ failures due to diabetes or its metabolic complications, such as diabetic ketoacidosis and hyperosmolar hyperglycemic state, if there is hemodynamic instability, failure to protect the airway, altered level of consciousness, or the presence of infectious states (especially those of lower respiratory tract).

Although the lungs are not thought to be primarily affected by DM, the finding of abnormal lung function in some diabetic subjects suggests that the lung should be considered a 'target organ' [2]. An increasing number of studies indicate physiological and structural abnormalities in the lung of both type 1 and type 2 diabetics. Decreased capacity of the antioxidative defense system and increased oxidative stress were seen in the lung of diabetic rats and rabbits [3].

Chronic hyperglycaemia is considered to be the main reason for diabetes complications. In the process of prolonged increased glucose concentration, the increased generation of reactive oxygen species (ROS) occurs, as well as the disturbances of pro- and antioxidative balance, i.e. the oxidative stress [4]. Intracellular oxidative stress and subsequent activation of the redox-sensitive transcription factor NF- $\kappa \mathrm{B}$ is supposed to play an important role in the development of late diabetic complications. NF- $\kappa \mathrm{B}$ is a pleiotropic transcription factor activated by low levels of ROS and inhibited by antioxidants and some antibiotics $[5,6]$.

NF- $\mathrm{BB}$ has been shown to activate, via transcription, the genes encoding pro-inflammatory cytokines (TNF, IL-1 $\beta$ and IL-12), cell adhesion molecules, nitric oxide synthase (NOS) and cyclo-oxygenase-2 [7, 8]. In attempting to limit the oxidative damage, a number of antioxidants have been tested. It has been proposed that antioxidants, which maintain the concentration of reduced glutathione (GSH), may restore the cellular defense mechanism and block lipid peroxidation and protein oxidation.

Increased oxidative stress in diabetic patients may lead to protein oxidation [9]. The conversion of proteins to protein carbonyl (PCC) derivatives occurs via direct oxidation by ROS, with the eventual formation of oxidized amino acids $[10,11]$. Oxidative modification of proteins in vivo may affect a variety of cellular functions. The best marker for intracellular oxidative stress-dependent cellular damage is the PCC content. The unique advantage of the carbonyl measurement as a good marker of oxidative stress is the fact that it covers a much wider range of oxidative damage than other markers do $[9,11-$ 14].
Pyrrolidine dithiocarbamate (PDTC) is a metal chelator and an antioxidant, and has potent anti-inflammatory properties due to its ability to suppress NF- $\kappa \mathrm{B}[7,15$, 16]. Keeping in mind that NF- $\kappa B$ activation may have a crucial role on the end-organ injury caused by DM, we studied the effects of PDTC on the inhibition of NF- $\kappa B$ activation and on possible lung injury due to streptozotocin-induced DM.

\section{Materials and Method}

\section{Study Design}

This controlled experiment was approved and reviewed by the animal care and use committee of Istanbul University. Thirty-six adult Sprague-Dawley rats (230-250 g) were acquired from the experimental animal laboratory of Istanbul University, Cerrahpasa Medical Faculty, and maintained in a 14-hour light/10-hour dark cycle. The rats were housed in cages in a controlled temperature room $\left(22-25^{\circ} \mathrm{C}\right)$ and fed on a standard pellet diet and tap water, ad libitum.

The experiment was performed on 4 groups of animals, 2 of which acted as controls. Experimental diabetes was induced by a single intraperitoneal (i.p.) injection of streptozotocin (STZ) (65 $\mathrm{mg} \mathrm{kg}^{-1}$ STZ; Sigma, Deisenhofen, Germany) dissolved in $0.1 \mathrm{M}$ sodium citrate buffer ( $\mathrm{pH}$ 4.5) [17]. Two days after the STZ injection, blood samples were collected from the tail vein, and blood glucose levels were determined by a glucometer. Rats with blood glucose levels higher than $250 \mathrm{mg} \mathrm{dl}^{-1}$ were accepted as diabetic. The diabetic rats in the PDTC group $(n=10)$ received, for a total of 10 weeks, $60 \mathrm{mg}$ day $^{-1}$ PDTC (Sigma-Aldrich, St. Louis, Mo., USA). The rats in control group $(n=8)$ received no treatment except for i.p. injections of sodium citrate buffer used to administer STZ to the diabetic groups, whereas the control group for PDTC $(n=8)$ comprised the rats given the same amount of PDTC in the same amount of time as the diabetic PDTC group, as well as i.p. sodium citrate. At the end of 10 weeks, the rats were sacrificed under Nembutal anaesthesia (50 $\mathrm{mg} \mathrm{kg}^{-1}$; Ulagay, Turkey) and their lungs were harvested.

\section{Histopathological Examination}

For the histopathological examination right lung tissue samples were fixed in $10 \%$ neutral buffered formaldehyde solution for $24 \mathrm{~h}$. After dehydration procedures the samples were blocked in paraffin, then cut in sections of $4 \mu \mathrm{m}$ and stained with hematoxylin and eosin (HE), and for the evaluation of basal membrane thickening they were also stained with periodic acid Schiff (PAS) staining. Mounted slides were examined under a light microscope (Nicon microscope ECLIPSE E600W, Tokyo, Japan) by 2 pathologists.

\section{Immunohistochemical Evaluation}

Specimens were processed for light microscopy and sections were incubated at $60^{\circ} \mathrm{C}$ overnight and then dewaxed in xylene for $30 \mathrm{~min}$. After being soaked in a decreasing series of ethanol, sections were washed with distilled water and phosphate-buffered saline (PBS) for $10 \mathrm{~min}$. Sections were then treated with $2 \%$ trypsin 
in $50 \mathrm{mM}$ Tris buffer ( $\mathrm{pH} 7.5$ ) at $37^{\circ} \mathrm{C}$ for $15 \mathrm{~min}$ washed with PBS. This was followed by their delineation with a Dako pen (Dako, Glostrup, Denmark) and incubation in a solution of $3 \% \mathrm{H}_{2} \mathrm{O}_{2}$ for $15 \mathrm{~min}$ to inhibit endogenous peroxidase activity. Then, the sections were incubated for $1 \mathrm{~h}$ at room temperature with endothelial nitric oxide synthase (eNOS) (eNOS rabbit Pab Neomarker, RB1711-P) and NF-кB/P65 (Rel A) Ab-1 (Neomarkers R-B-1638-R7) antibodies at a 1:50 dilution. Ultra vision HRP-AEC (3-amino-9ethyl carbazole) staining protocol was used in this stage. The colored product was developed following an incubation period of 5 min with AEC substrate kit (TA-004-HAC; Lab Vision). Having been washed in distilled water, the slides were counterstained with hematoxylin and mounted in glycerol gelatin [18].

The staining of cytoplasmic eNOS in the interstitial and alveolar endothelial cells and epithelial cells was evaluated, and the results were expressed as the percentage of interstitial and alveolar endothelial cells and epithelial cells cytoplasmically stained positive for eNOS in 1,000 cells counted in the same section.

The cases were evaluated for diffuseness and intensity of staining. According to staining diffuseness, sections were graded as follows: 0 = no staining; 1 = less than $25 \%$ staining; 2 = staining between 25 and 50\%; 3 = staining between 50 and $75 \%$; $4=$ more than $75 \%$ staining. According to staining intensity, sections were graded as follows: $0=$ no staining; $1=$ weak but detectable above control; 2 = distinct; 3 = intense staining. Immunohistochemical scores were obtained by adding diffuseness and intensity subscores.

\section{Biochemical Evaluations}

All tissues were washed twice with cold saline solution and immediately stored at $-80^{\circ} \mathrm{C}$ for the measurement of superoxide dismutase (SOD), GSH and PCC levels. Tissues were homogenized in a 4 volumes of ice-cold buffer containing $20 \mathrm{mM}$ Tris, 10 mM EDTA (pH 7.4)

GSH level was determined by the spectrophotometric method of Elman [19] based on the development a yellow color with the addition of 5,5' dithiobis-2-nitrobenzoic acid to compounds containing sulfhydryl groups. The results are expressed as nmol/g wet tissue.

SOD activity was measured with a modified method of Sun et al. [20]. This assay involved the inhibition of nitroblue tetrazolium reduction, with xanthine oxidase used as a superoxide generator. The reaction mixture consisted of $40 \mathrm{ml}$ of $0.3 \mathrm{mmol} / \mathrm{l}$ xanthine solution, $20 \mathrm{ml}$ of $0.6 \mathrm{mmol} / \mathrm{l}$ EDTA solution, $12 \mathrm{ml}$ of $400 \mathrm{mmol} / 1 \mathrm{Na}_{2} \mathrm{CO}_{3}$, and $6 \mathrm{ml}$ of bovine serum albumin. The final concentration of xanthine oxidase was 167 U/l. Formazan production was measured spectrophotometrically at $560 \mathrm{~nm}$.

Tissue protein levels were determined by the method of Lowry et al. [21]. PCC levels were measured according to the method based on spectrophotometric detection of the reaction of 2,4-dinitrophenylhydrazine with protein carbonyl to form protein hydrazones [14].

\section{Analysis}

Statistical analyses of the histopathologic and immunohistochemical evaluation of the groups were carried out by $\chi^{2}$ test and analyses of the other data were compared by 1-way ANOVA followed by Tukey multiple comparison tests. Results of all groups were shown as mean values \pm standard deviation (SD). $\mathrm{p}<0.05$ was accepted as a statistically significant value.
Table 1. Comparisons of GSH, SOD and PCC between groups

\begin{tabular}{lcll}
\hline & $\begin{array}{l}\text { GSH, nmol/ } \\
\text { mg protein }\end{array}$ & $\begin{array}{l}\text { SOD, U/mg } \\
\text { protein }\end{array}$ & $\begin{array}{l}\text { PCC, nmol/ } \\
\text { mg protein }\end{array}$ \\
\hline Control & $2.15 \pm 0.39$ & $9.39 \pm 1.34$ & $0.98 \pm 0.27$ \\
Control + PDTC & $2.12 \pm 0.33$ & $9.31 \pm 1.4$ & $0.92 \pm 0.23$ \\
\hline Diabetes & $1.3 \pm 0.42^{\mathrm{a}, \mathrm{b}}$ & $6.83 \pm 1.41^{\mathrm{a}, \mathrm{b}}$ & $2.07 \pm 0.91^{\mathrm{a}, \mathrm{b}}$ \\
Diabetes + PDTC & $2.01 \pm 0.47$ & $8.21 \pm 1.23$ & $1.09 \pm 1.31$
\end{tabular}

a Statistically significant vs. control groups $(\mathrm{p}<0.05)$.

${ }^{\mathrm{b}}$ Statistically significant vs. group receiving PDTC $(\mathrm{p}<0.05)$.

\section{Results}

There was no significant difference in terms of body weight between the control and experimental groups, and the 2 control groups revealed nearly exactly similar results in all aspects $(\mathrm{p}>0.05)$.

The measurements of protein carbonyl content was significantly lower $(\mathrm{p}<0.05)$ and those of SOD and GSH were higher $(\mathrm{p}<0.05, \mathrm{p}<0.01$, respectively) in the lungs of the diabetes + PDTC group compared with the diabetes group. However, there was no significant difference between the controls and diabetes + PDTC group ( $p>$ $0.05)$ concerning these parameters (table 1).

Light microscopy revealed that alveolar basal membranes were thickened in diabetic lungs. Furthermore, there were mononuclear inflammatory cells infiltrating into the interstitium in STZ-induced diabetic lungs. But these histopathological changes were diminished in the PDTC group (fig. 1).

As a result of the immunohistochemical evaluation, it was found that positive expressions of eNOS and p65 staining were more intense in diabetic lungs than in those of the control groups $(\mathrm{p}<0.05)$. However, there were poor or mild positive expressions of eNOS and p65 activity in the PDTC group, a finding which was similar to the control groups (fig. 2, 3; table 2).

\section{Discussion}

In the present study, it was seen that diabetes caused some alterations in antioxidant capacity and structural deterioration in the rat lungs with the activation of NF$\kappa B$. Treatment with PDTC, a specific inhibitor of NF- $\kappa$ B, reduced biochemical and structural derangement of diabetic lungs. 

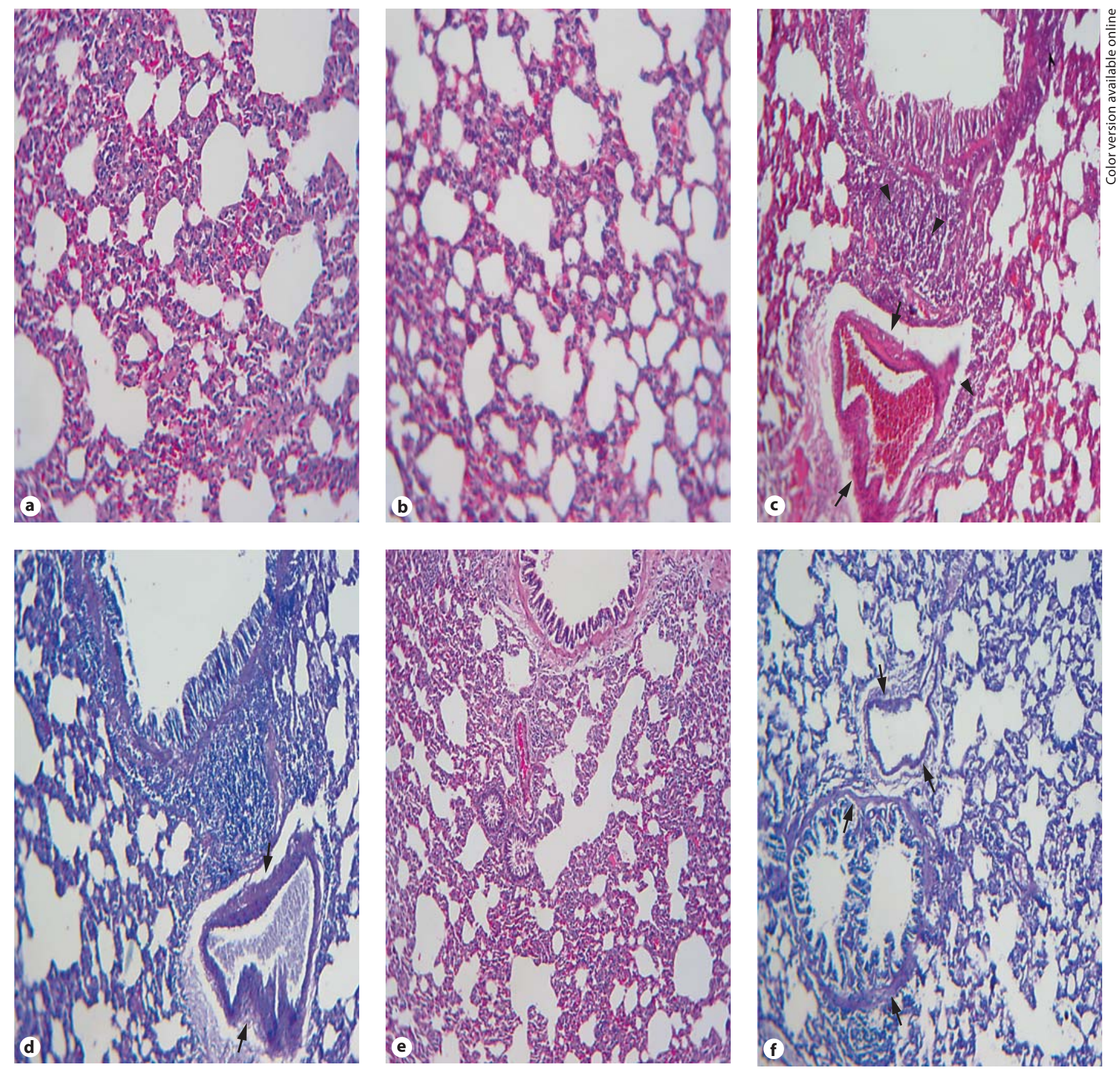

Fig. 1. The light microscopic images of lung tissues of control (a) and control + PDTC (b). Both HE. $\times 100$. c Thickened basal membranes (arrows) and intense mononuclear cell infiltration (arrowheads) in the diabetic lung. HE. $\times 100$. d Thickened basal membranes in diabetic lung are easily seen with PAS staining (arrows). $\times 100$. e PDTC-treated diabetic rat lung tissue with less inflammatory reaction. HE. $\times 40$. $\mathbf{f}$ Less thickening of basal membranes (arrows). PAS. $\times 100$. 
Fig. 2. eNOS levels in control (a) and control + PDTC (b), diabetic (c) and PDTCtreated diabetic lungs (d). Poor eNOS staining in controls (a and b; IHC, $\times 40$ and $\times 100$, respectively). c Diffuse eNOS staining in diabetes (arrows). IHC. $\times 100$. d Mild eNOS expressions in diabetes + PDTC (arrows). IHC. $\times 100$. IHC $=$ Immunohistochemical staining.

Table 2. Immunohistochemical (IHC) staining scores
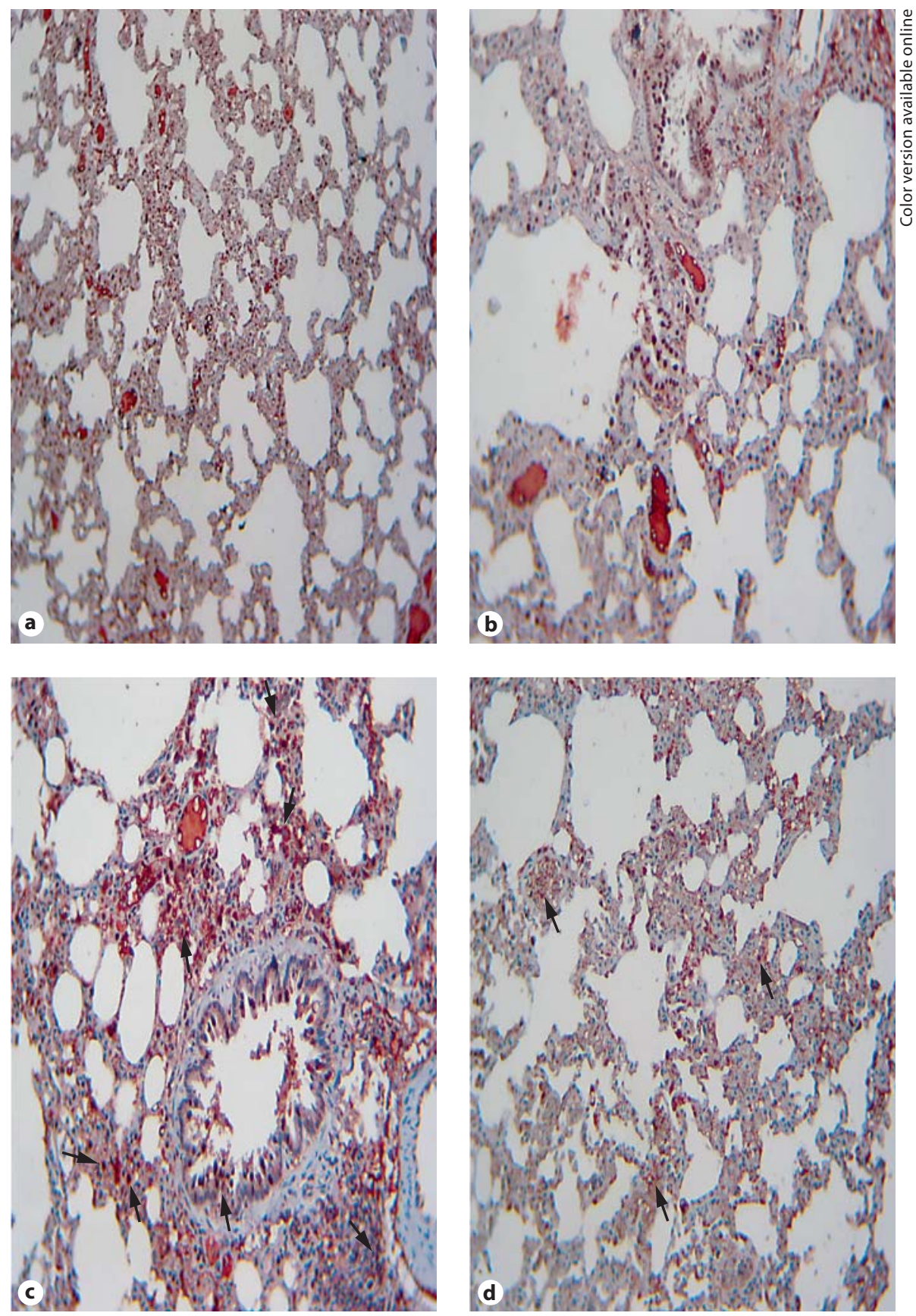

\begin{tabular}{lllllllll}
\hline IHC staining eNOS/p65 & 0 & 1 & 2 & 3 & 4 & 5 & 6 & 7 \\
\hline Control & $3 / 5$ & $3 / 3$ & $2 /-$ & & & & & \\
Control + PDTC & $2 / 5$ & $4 / 3$ & $2 /-$ & - & - & - & - & - \\
\hline Diabetes & - & - & - & $2 /-$ & $3 / 3$ & $2 / 1$ & $2 / 3$ & $1 / 3$ \\
Diabetes + PDTC & $-/ 1$ & $6 / 3$ & $3 / 3$ & $1 / 3$ & - & - & - & -
\end{tabular}

Numbers of samples revealing eNOS and p65 subscores between 0 and 7 are presented. 

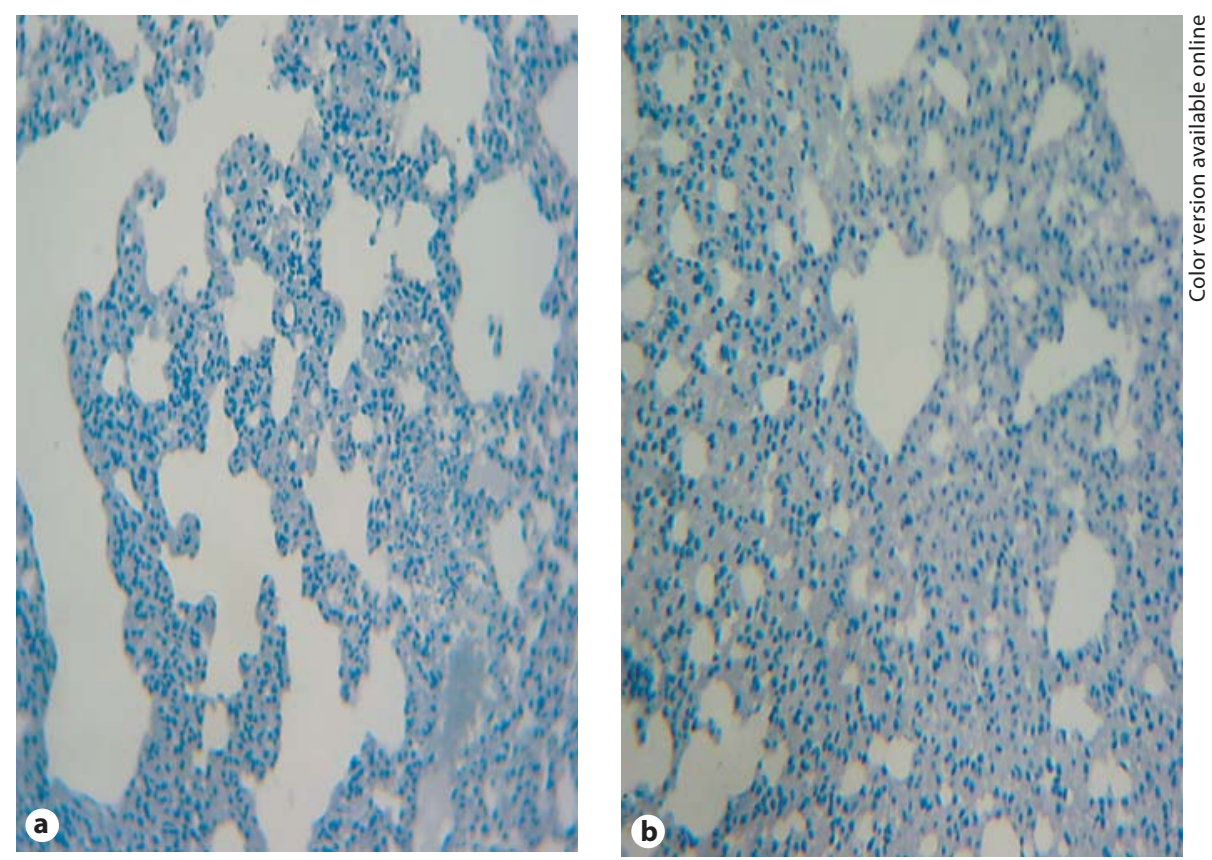

Fig. 3. p65 activities in lung tissues are shown. a, b There is no p65 activity at all in the control group and control + PDTC group. IHC. $\times 40$. c However, there is diffuse activity in diabetic lung (arrows). IHC. $\times 40$. $\mathbf{d}$ In the diabetes + PDTC sample, it is clearly seen that p65 activity is diminished compared to the one in diabetic lung. IHC (arrows). $\times 100$. IHC $=$ Immunohistochemical staining.
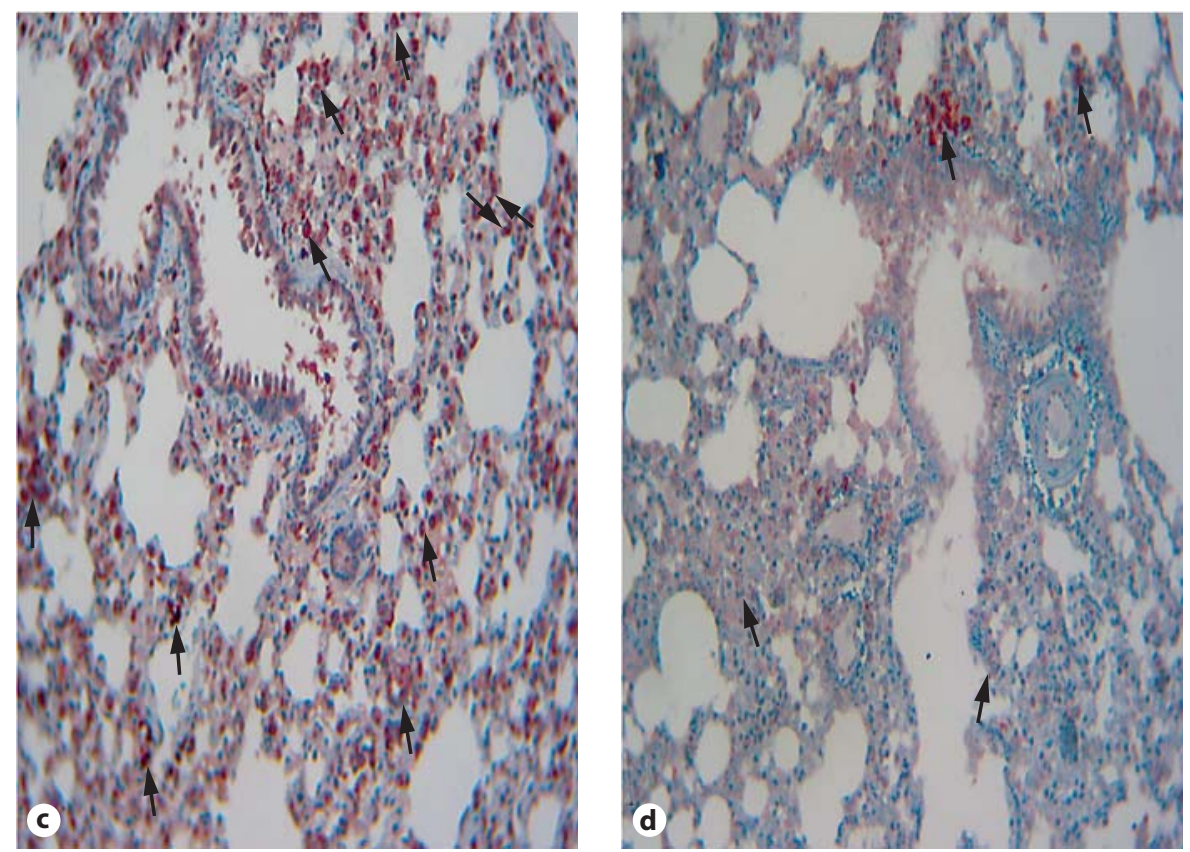

DM primarily affects the vessels, heart, kidneys, retina and central nervous system, and causes end-organ injuries, among which the lungs are seldom mentioned. However, abnormal pulmonary function has been detected in some diabetic patients and experimental data suggest that the lung is also a target organ [2]. Basal lamina thickening of capillaries and epithelia in lungs were reported in a study conducted by Weynand et al. [22] Nonenzymatic glycosylation-induced alteration of lung connective tissue is the most likely pathogenic mechanism underlying pulmonary microangiopathy. Apart from the findings of microangiopathy, in the study by Popov and Simionescu [23], diabetic animals displayed pulmonary intravascular macrophages relevant for pul- 
monary inflammation and associated injury. Our study is in accordance with those mentioned above as it demonstrated that diabetes caused alveolar injury and inflammation, but that such conditions decreased in severity with the use of the NF- $\kappa B$ inhibitor PDTC.

The duration of diabetes and the quality of glycemic control are important predictors for the prevelance of late diabetic complications in which diabetic lung injury seems to happen, as was confirmed by previous clinical and animal studies. One signal transduction pathway by which hyperglycemia might contribute to late diabetic complications is the activation of the transcription factor $\mathrm{NF}-\mathrm{\kappa B}$, which is induced by high glucose concentrations, advanced glycation end-products and oxidative stress $[24,25]$.

The endogenous antioxidant enzymes, including GSH, SOD and catalase, function to maintain redox equilibrium. However, in situations such as chronic hyperglycemia, the compensatory response is inadequate, leading to both ROS formation and activation of stress- and redoxsensitive gene expression via transcription factor NF- $\mathrm{\kappa B}$. It has been demonstrated that shear stress-induced upregulation of eNOS is mediated by NF- $\mathrm{kB}$. A study by Zhen et al. [26] has suggested that ROS-stimulated upregulation of eNOS expression is mediated by diminished $\mathrm{NO}$ availability and consequent reduction in the negative feedback regulatory action of NO on eNOS expression, which is possibly mediated by NF- $\mathrm{B}$. Taking these facts into consideration, in this study, we sought to determine if eNOS is activated by NF- $\kappa \mathrm{B}$ in the lungs of rats with diabetes, and found that $\mathrm{eNOS}$ and $\mathrm{p} 65$ expressions were significantly reduced in diabetic rats treated with PDTC.

$\mathrm{NO}$ is normally produced from L-arginine by eNOS in the vasculature. NO easily reacts with superoxide, generating the highly reactive molecule $\mathrm{ONOO}^{-}$, and triggering a cascade of harmful events $[27,28]$. Therefore its chemical environment [i.e. presence of free radical superoxide $\left(\mathrm{O}_{2}^{-}\right)$] determines whether $\mathrm{NO}$ exerts protective or harmful effects. $\mathrm{O}_{2}^{-}$is produced by one electron reduction of oxygen by several different oxidases including $\mathrm{NAD}(\mathrm{P}) \mathrm{H}$ oxidase, xanthine oxidase, cyclooxygenase and even eNOS under certain conditions, as well as by the mitochondrial electron transport chain during the course of normal oxidative phosphorylation. $\mathrm{O}_{2}^{-}$is quickly eliminated by antioxidant defense mechanisms and dismutated to $\mathrm{H}_{2} \mathrm{O}_{2}$ by manganese superoxide dismutase ( $\mathrm{Mn}$ $\mathrm{SOD}$ ) in the mitochondria and by $\mathrm{Cu}-\mathrm{SOD}$ in the cytosol. $\mathrm{H}_{2} \mathrm{O}_{2}$ is, in turn, converted to $\mathrm{H}_{2} \mathrm{O}$ and $\mathrm{O}_{2}$ by glutathione peroxidase [29].
Unlike eNOS expressions in other organs, eNOS levels in lungs in diabetes may increase as shown in a research carried out by Sridulyakul et al. [30], who concluded that high, not low, flow-mediated eNOS expression is a good measure of hyperglycemic-induced endothelial dysfunction. Similarly, the immunohistochemical results of our study revealed that eNOS expression increased in the lungs of diabetic rats but decreased in those treated with PDTC. This allows us to maintain that eNOS expression can be inhibited by NF- $\kappa$ B antagonism.

Generation of ROS is induced by many oxidants like toxins, alcohol, radiation and hyperglycemia, just to name a few $[4,31,32]$. The development of tissue injury probably depends on the balance between the production of ROS and tissue antioxidant defense mechanism. Reduced glutathione is a major intracellular redox buffer and glutathione functions as a direct free-radical scavenger, as a cosubstrate for glutathione peroxidase activity, and as a cofactor for many enzymes in xenobiotic reactions. There are studies in which glutathione concentration is found to decrease in the liver, kidney, pancreas, plasma, red blood cells, nerve and pre-cataractous lenses of chemically induced diabetic animals [33]. However, to our knowledge, there are few studies on lung glutathione levels in cases with diabetes. The present study may therefore be of some interest to other researchers as it revealed that reduced glutathione levels, which decrease in diabetic lungs, become normal by the use of PDTC.

In a few reports about diabetic lungs, including the one by Hurdag et al. [17], SOD was found to be decreased and it increased with the use of antioxidants. Hurdag et al. also reported that the increased intensity of immunostaining for eNOS they showed diminished by use of the antioxidant $\alpha$-lipoic acid. Similarly, it was found in this study that NF- $\kappa \mathrm{B}$ inhibitor PDTC caused an elevation in decreased SOD activity while diminishing the elevated eNOS expression in diabetic lung tissue.

Another significant finding of this study is that diabetes caused alterations in the antioxidant enzyme capacity of lungs with increased protein carbonylation. Protein carbonyl content is actually the most general indicator and by far the most commonly used marker of protein oxidation, and accumulation of protein carbonyls has been observed in several human diseases including Alzheimer's disease, diabetes, inflammatory bowel disease and arthritis. Carbonyl groups (aldehydes and ketones) are produced on protein side chains when they are oxidized. These moieties are chemically stable, which is useful for both their detection and storage [34]. Most 
protein carbonyl assays are advantageous in that they require no special or expensive equipment. As a result, they can be performed in any normally equipped biochemistry laboratory. The best marker for intracellular oxidative stress-dependent cellular damage is the PC content. The unique advantage of the carbonyl measurement as a good marker of oxidative stress is that it covers a much wider range of oxidative damage than do the other markers $[10,12,13,35]$. We found increased protein carbonyl levels in diabetic lung, and our data are in agreement with other investigators and confirm the presence of increased oxidative protein damage in DM $[9,12,36]$.

\section{Conclusion}

Based on the new developments in our understanding of the pathophysiology of oxidative stress, it is clear that strategies to block the formation of reactive radicals and prevent their triggering the oxidative mechanism, namely the activation of NF- $\mathrm{B}$, will provide a targeted and causal approach to provide conclusive evidence whether antioxidants should be part of the end-organ injury treatment plan in diabetes.

To the best of our knowledge, our study is the first to evaluate the effect of PDTC on lung injury caused by diabetes mellitus. Our results encourage us to assert that PDTC can be useful to prevent diabetic lung injury induced by oxidative stress. However, there is need for further studies on this issue before clinical application becomes possible.

\section{References}

1 Keays R: Diabetes. Curr Anaesth Crit Care 2007;18:69-75.

2 Sandler M: Is the lung a 'target organ' in diabetes mellitus? Arch Intern Med 1990;150: 1385-1388

3 Oztay F, Kandil A, Gurel E, Ustunova S, Kapucu A, et al: The relationship between nitric oxide and leptin in the lung of rat with streptozotocin-induced diabetes. Cell Biochem Funct 2008;26:162-171.

4 Błaszczak R, Kędziora J, Ertel D, Rutkowski $\mathrm{M}$, et al: Selected antioxidative enzyme activities in patients with diabetes mellitus type 2. Arch Med Sci 2005;1:144-147.

5 Schwartz MD, Moore EE, Moore FA, Shenkar R, Moine P, Haenel JB, Abraham E: Nuclear factor-kappa B is activated in alveolar macrophages from patients with the acute respiratory distress syndrome. Crit Care Med 1996;24:1285-1292.

6 He Z, Li B, Yu L, Liu Q, Zhong N, Ran P: Suppression of oxidant-induced glutathione synthesis by erythromycin in human bronchial epithelial cells. Respiration 2008; 75 : 202-209.

7 Cuzzocrea S, Chatterjee PK, Mazzon E, Dugo L, et al: Pyrrolidine dithiocarbamate attenuates the development of acute and chronic inflammation. Br J Pharma 2002; 135:496-510.

8 Yagi O, Aoshiba K, Nagai A: Activation of nuclear factor-kappaB in airway epithelial cells in patients with chronic obstructive pulmonary disease. Respiration 2006; 73 : 610-616.
9 Telci A, Cakatay U, Kayali R, Erdogan C, Orhan Y, Sivas A, Akcay T: Oxidative protein damage in plasma of type 2 diabetic patients. Horm Metab Res 2000;32:40-43.

10 Carrard G, Bulteau AL, Petropoulos I, Friguet B: Impairment of proteasome structure and function in aging. Int $\mathrm{J}$ Biochem Cell Bio 2002;34:1461-1474.

11 Stadtman ER, Levine RL: Protein oxidation, Ann NY Acad Sci 2000;899:191-208.

12 Cakatay U, Telci A, Kayali R, Tekeli F, Akcay T, Sivas A: Relation of aging with oxidative protein damage parameters in the rat skeletal muscle. Clin Biochem 2003;36:51-55.

13 Evans P, Lyras L, Halliwell B: Measurement of protein carbonyls in human brain tissue. Method Enzymol 1999;300:145-156.

14 Reznik AZ, Packer L: Oxidative damage to proteins: spectrophotometric method for carbonyl assay. Method Enzymol 1994;233: 357-363.

15 Tugcu V, Ozbek E, Tasci AI, Kemahli E, Somay A, Bas M, et al: Selective nuclear factor kappa-B inhibitors, pyrolidium dithiocarbamate and sulfasalazine, prevent the nephrotoxicity induced by gentamicin. BJU Int 2006;98:680-686.

16 Tugcu V, Ozbek E, Kemahli E, Cekmen MB, et al: Rapid communication: protective effect of a nuclear factor kappaB inhibitor, pyrrolidium dithiocarbamate, in the kidney of rats with nephrolithiasis induced by ethylene glycol. J Endourol 2007;21:1097-1106.

17 Hurdag C, Uyanerb I, Gurelb E, Utkusavas A, Atukerend P, Demirci C: The effect of $\alpha$ lipoic acid on NOS dispersion in the lung of streptozotocin-induced diabetic rats. J Diabetes Complicat 2008:22:56-61.
18 McNaughton L, Puttagunta L, MartinezCuesta MA, Kneteman N, Mayers I, Moqbel $\mathrm{R}$, et al: Distribution of nitric oxide synthase in normal and cirrhotic human liver. P Natl Acad Sci USA 2002;2499:17161-17166.

19 Elman GL: Tissue sulfhydryl groups. Arch Biochem Biophys1959;82:70-77.

20 Sun Y, Oberley LW, Li YA: Simple method for clinical assay of superoxide dismutase. Clin Chem 1988;34:497-500.

21 Lowry OH, Rosebrough NJ, Farr AC, Randall RJ: Protein measurement with the folinphenol reagent. J Biol Chem 1951;193:265.

22 Weynand B, Jonckheere A, Frans A, Rahier $\mathrm{J}$ : Diabetes mellitus induces a thickening of the pulmonary basal laminae. Respiration 1999;66:14-19.

23 Popov D, Simionescu M: Alterations of lung structure in experimental diabetes and diabetes associated with hyperlipidemia in hamsters. Eur Respir J 1997;10:1850-1858.

24 Huebschmann AG, Regensteiner JG, Vlassara H, Reusch J: Diabetes and advanced glycoxidation end products. Diabetes Care 2006;29:1420-1432.

25 Bierhaus A, Chevion S, Chevion M, Hofmann $M$, Quehenberger P, Illmer T, et al: Advanced glycation end product-induced activation of NF-kappaB is suppressed by alpha-lipoic acid in cultured endothelial cells. Diabetes 1997;46:1481-1490.

26 Zhen J, Lu H, Wang XQ, Vaziri ND, Zhou XJ: Upregulation of endothelial and inducible nitric oxide synthase expression by reactive oxygen species. Am J Hypertens 2008;21:2834. 
27 Turko IV, Marcondes S, Murad F: Diabetesassociated nitration of tyrosine and inactivation of succinyl-CoA:3-oxoacid CoA-transferase. Am J Physiol Heart Circ Physiol 2001; 281:2289-2294.

28 Vega-Lopez S, Devaraj S, Jialal I: Oxidative stress and antioxidant supplementation in the management of diabetic cardiovascular disease. J Investig Med 2004;52:24-32.

29 Johansen JS, Harris AK, Rychly DJ, Ergul A: Oxidative stress and the use of antioxidants in diabetes: Linking basic science to clinical practice. Cardiovasc Diabetol 2005;4:5. DOI: 10.1186/1475-2840-4-5.
30 Sridulyakul P, Chakraphan D, Bhattarakosol P, Patumraj S: Endothelial nitric oxide synthase expression in systemic and pulmonary circulation of streptozotocin induced diabetic rats: comparison using image analysis Clin Hemorheol Micro 2003;29:423-428.

31 Aytacoglu BN, Calikoglu M, Tamer L, Coşkun B, Sucu N, Köse N, Aktas S, Dikmengil M: Alcohol-induced lung damage and increased oxidative stress. Respiration 2006;73:100-104.

32 Yao J, Liu Y, Wang X, Shen Y, Yuan S, Wan Y, Jiang Q: UVB radiation induces human lens epithelial cell migration via NADPH oxidase-mediated generation of reactive oxygen species and up-regulation of matrix metalloproteinases. Int J Mol Med 2009;24:153159.
33 Maritim AC, Sanders RA, Watkins JB: Diabetes, oxidative stress, and antioxidants: a review. J Biochem Mol Toxic 2003;17:24-38.

34 Berlett BS, Stadtman ER: Protein oxidation in aging, disease, and oxidative stress. Am Soc Biochem Mol Biol 1997;272:2031320316.

35 Dursun E, Timur M, Dursun B, Süleymanlar G, Ozben T: Protein oxidation in type 2 diabetic patients on hemodialysis. J Diabetes Complicat 2005; 19:142-146.

36 Aso Y, Inukai T, Tayama K, Takemura Y: Serum concentrations of advanced glycation endproducts are associated with the development of atherosclerosis as well as diabetic microangiopathy in patients with type 2 diabetes. Acta Diabetol 2000;37:87-92. 